\title{
ARTICLE OPEN Replicable association between human cytomegalovirus infection and reduced white matter fractional anisotropy in major depressive disorder
}

Haixia Zheng (DD ${ }^{1}$, Maurizio Bergamino ${ }^{1,2}$, Bart N. Ford ${ }^{1}{ }^{1}$, Rayus Kuplicki ${ }^{1}$, Fang-Cheng Yeh ${ }^{3}$, Jerzy Bodurka ${ }^{1,4}$, Kaiping Burrows ${ }^{1}$, Tulsa 1000 Investigators, Peter W. Hunt ${ }^{5}$, T. Kent Teague ${ }^{6,7,8}$, Michael R. Irwin ${ }^{9,10,11}$, Robert H. Yolken ${ }^{12}$, Martin P. Paulus (iD ${ }^{1,13}$ and Jonathan Savitz (D) ${ }^{1,13}$

\begin{abstract}
Major depressive disorder (MDD) is associated with reductions in white matter microstructural integrity as measured by fractional anisotropy (FA), an index derived from diffusion tensor imaging (DTI). The neurotropic herpesvirus, human cytomegalovirus (HCMV), is a major cause of white matter pathology in immunosuppressed populations but its relationship with FA has never been tested in MDD despite the presence of inflammation and weakened antiviral immunity in a subset of depressed patients. We tested the relationship between FA and HCMV infection in two independent samples consisting of 176 individuals with MDD and 44 healthy controls (HC) (Discovery sample) and 88 participants with MDD and $48 \mathrm{HCs}$ (Replication sample). Equal numbers of HCMV positive $(\mathrm{HCMV}+)$ and $\mathrm{HCMV}$ negative $(\mathrm{HCMV}-)$ groups within each sample were balanced on ten different clinical/demographic variables using propensity score matching. Anti-HCMV IgG antibodies were measured using a solid-phase ELISA. In the Discovery sample, significantly lower FA was observed in the right inferior fronto-occipital fasciculus (IFOF) in HCMV+ participants with MDD compared to HCMV - participants with MDD (cluster size $1316 \mathrm{~mm}^{3} ; p_{\mathrm{FWE}}<0.05, d=-0.58$ ). This association was confirmed in the replication sample by extracting the mean FA from this exact cluster and applying the identical statistical model $(p<0.05, d=$ $-0.45)$. There was no significant effect of diagnosis or interaction between diagnosis and HCMV in either sample. The effect of chronic HCMV infection on white matter integrity may-in at-risk individuals-contribute to the psychopathology of depression. These findings may provide a novel target of intervention for a subgroup of patients with MDD.
\end{abstract}

Neuropsychopharmacology (2021) 46:928-938; https://doi.org/10.1038/s41386-021-00971-1

\section{INTRODUCTION}

Inflammatory processes have been hypothesized to play a significant role in the development of major depressive disorder (MDD) [1-3]. This pattern of chronic inflammation tends to cooccur with impairments to the adaptive immune system, weakening anti-viral immunity in MDD [4-7]. Specifically, in vitro studies of immune cells from depressed and chronically-stressed individuals are indicative of a decreased proliferative response of lymphocytes to mitogens, decreased natural killer cell function, and lymphopenia $[8,9]$. Gene expression studies indicate downregulated expression of genes involved in anti-viral immunity [4-6]. In vivo, experimental studies demonstrate that subjects exposed to rhinovirus or influenza are more likely to become infected and show clinical symptoms if they endorse recent stress or are lonely [10-13]. Further, depression is associated with impairment of vaccine-induced immunity to the varicella-zoster virus $[14,15]$ and hepatitis B virus [16], a loss of childhood vaccine-induced immunity to measles [17], and impaired control of chronic viral infections [18-20]. This study focuses on the potential sequalae of one such chronic infection in MDD-human cytomegalovirus (HCMV).

HCMV is a common herpesvirus that establishes lifelong latent infections in approximately $50 \%$ of the US population via its ability to manipulate and evade the immune system [21, 22]. HCMV persists in myeloid lineage cells but can also infect endothelial cells of the blood-brain barrier, glia, and neurons [23-26]. This neurotropism may explain why HCMV is an important cause of neurological disease in HIV patients and why HCMV infection in utero can have serious neurodevelopmental and neuropsychological sequelae, including mental retardation, cerebral palsy, and sensorineural hearing loss [27-29]. In contrast, primary HCMV infection and its periodic reactivation are usually considered benign in medically-healthy populations. However, activation of latent HCMV infection can occur in response to inflammatory challenge or stress [30-35]. Some evidence suggests that such

\footnotetext{
${ }^{1}$ Laureate Institute for Brain Research, Tulsa, OK, USA; ${ }^{2}$ Division of Neuroimaging Research, Barrow Neurological Institute, Phoenix, AZ, USA; ${ }^{3}$ Department of Neurological Surgery,

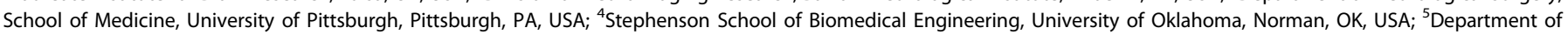

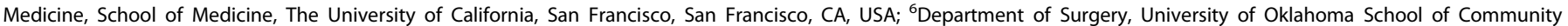

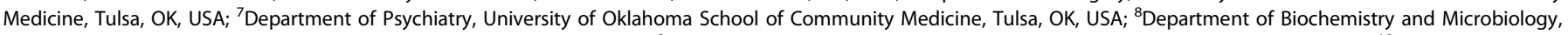

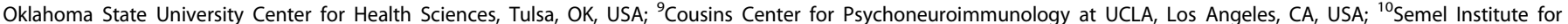

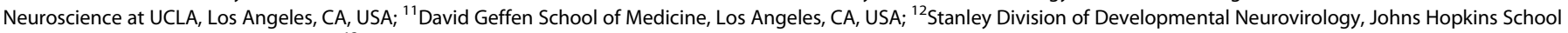
of Medicine, Baltimore, MD, USA and ${ }^{13}$ Oxley College of Health Sciences, The University of Tulsa, Tulsa, OK, USA

Correspondence: Haixia Zheng (hzheng@laureateinstitute.org)

A list of authors and their affiliations appears at the end of the paper.
}

Received: 13 October 2020 Revised: 23 December 2020 Accepted: 12 January 2021

Published online: 26 January 2021 
activation contributes to inflammation-related pathology in several autoimmune disorders [36], and is a risk factor for adverse outcomes in sepsis patients [37]. Notably, these pathological effects may extend to the brain. For instance, HCMV positive $(\mathrm{HCMV}+)$ multiple sclerosis patients showed greater brain atrophy over time than $\mathrm{HCMV}$ negative (HCMV-) patients [38] and higher HCMV IgG titers (indicative of greater HCMV reactivation) during a first demyelinating event predicted greater loss of gray matter volume over time [38]. Similarly, higher lifetime HCMV antibody levels and a greater $\mathrm{CD}^{+}$response to HCMV antigen were associated with the presence of neurofibrillary tangles and a diagnosis of Alzheimer's disease at postmortem [39].

Activation of the sympathetic nervous system, possibly induced by stress, is thought to be an effector mechanism that promotes reactivation of HCMV [30]. Higher HCMV IgG titers have been reported in medical students during exams [31, 32], in female caregivers to disabled children [35], and in astronauts directly before and after space travel [33,34]. Given the well-established association between MDD, stress, and inflammation [1, 2], it is conceivable that HCMV may be more prone to reactivation in MDD populations. Indeed, HCMV has been associated with depression in at least 13 studies [40-53]. In our recent work, we found that HCMV infection was associated with reduced gray matter volume in participants with MDD but not healthy controls [54]. However, the link between HCMV and brain abnormalities in the context of psychiatric illness has received very little attention despite the fact that there may be potential treatment implications given the availability of anti-HCMV medications and the ongoing development of HCMV vaccines $[55,56]$.

The oligodendroglia responsible for white matter myelination are thought to be particularly vulnerable to the damaging effects of viral infections and inflammatory processes $[3,57,58]$, potentially explaining why one of the most prominent findings in MDD at postmortem is a reduction in the number or density of oligodendrocytes $[3,59]$. The fractional anisotropy (FA) value derived from diffusion tensor imaging (DTI) has been reported to be highly sensitive to axon myelination $[60,61]$ (although it likely also serves as a general index of neuronal integrity reflecting a combination of myelination, neural fiber compactness, axon diameter, and orientation [62]). Thus, this study investigated whether HCMV serostatus was associated with white matter microstructural integrity (FA) in the context of MDD. We hypothesized that relative to seronegative MDD participants, seropositive MDD participants would show reduced FA of major white matter tracts in the brain.

\section{METHODS}

Participants

Two independent groups of participants were involved in the study, 303 participants in the Discovery sample, and 202 in the Replication sample. Both Discovery and Replication sample participants were aged $18-55$ years and either had no personal history of psychiatric illness (healthy controls, $\mathrm{HC}$ ) or received a DSM-V diagnosis of MDD (with or without comorbid anxiety) based on the Mini International Neuropsychiatric Inventory (MINI) [63]. Participants completed the Patient-Reported Outcomes Measurement Information System (PROMIS) [64] scales for depression and anxiety, Patient Health Questionnaire 9 (PHQ-9) [65] for depressive symptoms, Customary Drinking and Drug use Record (CDDR) structured interview for lifetime alcohol use [66], as well as the childhood trauma questionnaire (CTQ) for early life stress [67]. For the Discovery sample, data were collected between January 2015 and February 2017. Exclusion criteria included: comorbid psychiatric disorders (except for anxiety disorders), substance use disorders (except for alcohol use disorder), neurological disorders, unstable medical disorders, a history of moderate-to-severe traumatic brain injury, a positive urine drug screen, a body mass index $(\mathrm{BMI})<17$ or $>38 \mathrm{~kg} / \mathrm{m}^{2}$, and general MRI exclusion criteria (details in the ref. [68]). For the Replication sample, data were collected from October 2018 and March 2020. The same exclusion criteria applied to the Replication sample except that the BMI cut-off was 40 and participants with a history of autoimmune disorders (except hypothyroidism) were also excluded. Approval for both studies was obtained from the Western Institutional Review Board and written informed consent was obtained from all participants.

\section{Anti-CMV IgG antibodies and C-reactive protein}

Plasma (Discovery sample) or serum (Replication sample) were isolated from morning blood samples following standard laboratory procedures and frozen at $-80^{\circ} \mathrm{C}$. Thawed samples were tested blind to diagnosis for IgG antibodies using a solid-phase ELISA (IBL America, catalog \#EI2570-9601G). A sample was considered HCMV seropositive if it had an optical density value $20 \%$ over the supplied cutoff standard, which is equivalent to approximately ten international units of antibody. Due to the nonnormal distribution, the density values were quantified as plateadjusted $z$-scores with a mean value for each plate of two and a standard deviation of one.

For the Discovery sample, serum concentrations of c-reactive protein (CRP) were analyzed with the V-PLEX Neuroinflammation Panel-1 Human Kit (Meso Scale Diagnostics) with the lowest level of quantification (LLOQ) of $0.027 \mathrm{mg} / \mathrm{L}$ and intra-assay and interassay coefficients of variation of 2 and $10 \%$, respectively. For the replication sample, CRP was measured using venous whole blood with the Diazyme high sensitivity (hs) CRP point of care (POC) test kit (\#DZ135B-SMA-discontinued) on the SMART 700 analyzer (Diazyme Laboratories). The measurement range was from 0.5 to $23 \mathrm{mg} / \mathrm{L}$.

\section{Image acquisition}

Diffusion MRI scans were acquired using two identical 3.0 T scanners (GE Discovery MR750) with brain-dedicated receive-only 32 element coil arrays optimized for parallel imaging (Nova Medical, Inc.). For the Discovery sample, the diffusion-weighted imaging (DWI) data were acquired using a single-shell acquisition with 60 diffusion encoding directions ( $b$ value $=1000 \mathrm{~s} / \mathrm{mm}^{2}$, TR/ $\mathrm{TE}=9000 / 83.6 \mathrm{~ms}$, with acquisition and reconstruction matrix $=$ $128 \times 128$, field of view $($ FOV $)=25.6 \times 25.6 \mathrm{~cm}$, slice thickness $=$ $2 \mathrm{~mm}$, without interslice spacing, 73 axial slices, acceleration factor $R=2$ in the phase encoding direction) and 8 no diffusionweighted images ( $b$ value $=0 \mathrm{~s} / \mathrm{mm}^{2}$ ) acquired at beginning of the scan. The total acquisition time was $10 \mathrm{~min}$ and $50 \mathrm{~s}$.

For the replication sample, the DWI data were acquired using a multiband sequence with acceleration factor 3 and multi-shell acquisition with 102 diffusion encoding directions $(b$ values $=500$, 1000,2000 , and $3000 \mathrm{~s} / \mathrm{mm}^{2}, \mathrm{TR} / \mathrm{TE}=4100 / 81.7 \mathrm{~ms}$, with acquisition and reconstruction matrix $=140 \times 140$, field of view $(F O V)=$ $24.0 \times 24.0 \mathrm{~cm}$, slice thickness $=1.7 \mathrm{~mm}$, without interslice spacing, 80 axial) and 12 no diffusion-weighted images. Total acquisition time was $7 \mathrm{~min}$ and $27 \mathrm{~s}$. For this sequence, a reverse phase-encoding acquisition with six no diffusion-weighted images $\left(b=0 \mathrm{~s} / \mathrm{mm}^{2}\right)$ and six diffusion-weighted images $(b=3000 \mathrm{~s} /$ $\mathrm{mm}^{2}$ ) was acquired to correct for EPI image distortions.

Individual-level image processing

DWI data were preprocessed using the FMRIB Software Library tool (FSL, version 6.0, https://fsl.fmrib.ox.ac.uk/fsl). Similar preprocessing steps were performed on both samples. The FSL "eddy" tool was used to estimate and correct eddy currentinduced distortions and gross participant movement [69]. The quality of the dataset was assessed using the eddy QC tools [70]. Slices with signal loss caused by participant movement coinciding with the diffusion encoding were detected and replaced by predictions made by a Gaussian Process [71]. The quality control 
criteria were set as average absolute volume to volume head motion of $<3 \mathrm{~mm}$ or total outliers $<5 \%$. Skull stripping was performed for each participant using FSL-Bet [72]. Tensor fitting and FA calculations were performed using the FSL-dtifit tool at each voxel in native space [73]. The Advanced Normalization Tools (ANTs) with asymmetric image normalization method coregistration algorithm was employed to normalize the FA maps to the FMRIB58_FA_1 $1 \mathrm{~mm}$ template [74]. The normalized images were visually inspected for alignment and then smoothed with a Gaussian kernel of $2 \mathrm{~mm}$ sigma (approximately $4.7 \mathrm{~mm}$ full width at half maximum) to increase the signal-to-noise ratio. A threshold of FA greater than 0.2 was used to construct a binary white mater mask across all participants. To minimize the partial volume effect, the final white matter mask consisted only of voxels that were nonzero in $100 \%$ of the sample. The Replication sample, only, was collected with reversed phase-encode blips which allowed for distortion correction. Therefore, the distortion correction using FSL-topup tool [75] was applied to the replication sample but not to the discovery sample.

\section{Covariates and propensity score matching}

To minimize potential selection bias on HCMV status, a propensity score matching approach was used in both discovery and replication samples. First, following the principles of confounder selection [76], ten variables that could theoretically influence the likelihood of HCMV infection, or cause white matter structure change, or both, were selected as potential confounders, i.e., age, sex, BMl, education, early-life stress (total CTQ score), psychotropic medication status, the severity of current symptoms of depression and anxiety, number of episodes (obtained from MINI interview), and the lifetime alcohol use (obtained from CDDR interview). Second, a small number of missing data points $(<3 \%)$ for these ten variables (Supplementary Table S8) were imputed by using the $k$ nearest neighbor algorithm with $k=10$ ( $\mathrm{R}, \mathrm{DMwR}$ package). Third, a multivariable logistic regression model was used to estimate the individual propensity score, which was defined as the likelihood of being HCMV + conditioned on the given set of covariates. Then a 1-to-1 matching (without caliper) was carried out to match $\mathrm{HCMV}+$ participants with $\mathrm{HCMV}-$ participants based on the nearest propensity score. This propensity matching process was implemented in MDD and $\mathrm{HC}$ groups separately. For the MDD group, the $\mathrm{HCMV}+$ and $\mathrm{HCMV}$ - subgroups were matched on all the ten covariates mentioned above. For the HC group, the HCMV + and HCMV - subgroups were matched on the same variables except for medication status. Thus, the matching process ensured that groups had similar baseline characteristics with respect to the given set of covariates, in theory, only differing on HCMV status. Additionally, for the Discovery sample, HC participants were matched with MDD participants on age, sex, BMl, and education using a ratio of 1:4. However, because the effect of depression on FA was not the main research question, in order to include as many participants as possible in Replication sample, we did not perform this between diagnostic group matching for the Replication sample.

\section{Group-level statistical analysis}

To test the effects of HCMV serostatus on white matter microstructure, whole-brain voxel-wise analyses were performed using 3dMVM, an AFNI-based multivariate modeling program [77]. Although we applied propensity score matching to adjust for selection bias, it was not possible to achieve an ideal balance of covariates (i.e., all the covariates' standardized mean differences between HCMV + and HCMV - groups of less than 0.1) [78] without pruning too many observations given our sample size. Therefore, three common covariates used in DTI studies (i.e., age, sex, and $\mathrm{BMI}$ ) were added in the multivariate regression model as covariates to further control for any potential imbalance that remained between the propensity-matched $\mathrm{HCMV}+$ and $\mathrm{HCMV}-$ groups. A discovery/replication approach was used to confirm the robustness of any findings. For the Discovery sample, a multiplecomparison correction was performed to determine significant clusters using Monte-Carlo simulations through AFNI's 3dClustSim and $3 \mathrm{dFWHMx}$ program which estimates spatial autocorrelation function parameters to determine the critical cluster size threshold of $p<0.005$ with an overall family-wise error (FWE) rate of $a<0.05$ $[79,80]$. Next, we generated a region of interest (ROI) binary mask which was determined by the clusters showing significant differences (FWE-corrected) in the Discovery sample. Subsequently, the mean FA value in the same cluster was extracted from the Replication sample by using the mask generated from the Discovery sample. The same statistical model was applied to test whether the ROI mean FA from the Replication sample was also significantly associated with HCMV status. The threshold for the confirmation test was set at $p<0.05$. Exploratory whole-brain voxel-wise analyses for the Replication sample are also reported for completeness using a voxel-level threshold of $p<0.05$, uncorrected. A population-averaged tractography atlas $(N=842)$ and DSI Studio (http://dsi-studio.labsolver.org/) was used to identify and visualize the major white matter tracts passing through significant clusters [81].

The relationship between the mean FA from the ROI and the anti-HCMV lgG level was examined within MDD $\mathrm{HCMV}+$ subgroups in both samples. CRP concentration was logtransformed and correlation analyses between $\mathrm{ROI}$ mean FA value and CRP concentration were performed within the MDD HCMV+ subgroups in both samples. The association between the mean FA from the ROI and depressive symptom severity (measured by each of the nine PHQ-9 items and the total PHQ-9 score) was tested in MDD groups by using a linear regression model with age, sex, and $\mathrm{BMI}$ as covariates. A two-sample $t$-test was performed to exam the symptom difference between $\mathrm{HCMV}$ - and HCMV + subgroups in participants with MDD.

Sensitivity analyses were implemented to test the robustness of the associations. That is, we ran two additional regression models; the first not adjusting for any of the potential confounders after the matching process, and the second adjusting for all ten covariates described above as well as head motion in the scanner after the matching process. Additionally, we calculated $E$-values [82] to evaluate the robustness of the results to potential unmeasured confounding.

\section{RESULTS}

Study population and covariate balance

Out of a total of 303 participants in the Discovery sample, we excluded 83 participants, and out of 202 participants in the Replication sample, we excluded 66 participants, leaving a total of 356 participants included in the group-level statistical analyses (Fig. 1). Demographic characteristics before propensity matching are summarized in Supplementary Table S1. After applying propensity matching, there were no statistically significant group differences in any of the measured covariates between HCMV+ and HCMV - subgroups in both sets of MDD and HC samples (Table 1). Demographic differences between HC and MDD groups are summarized in Supplementary Table S2. Detailed medication and comorbidity characteristics of the participants with MDD are summarized in Supplementary Table S3.

\section{Effect of HCMV}

We hypothesized that the effects of HCMV on WM microstructure would be most salient in the context of depression. We therefore tested for HCMV effects within the MDD and HC groups, separately. In the Discovery sample, significantly lower FA was observed in the right inferior fronto-occipital fasciculus (IFOF) in $\mathrm{HCMV}+$ participants with MDD compared to HCMV - participants with MDD (Figs. 2 and 3). The HCMV + and HCMV - HC groups did 


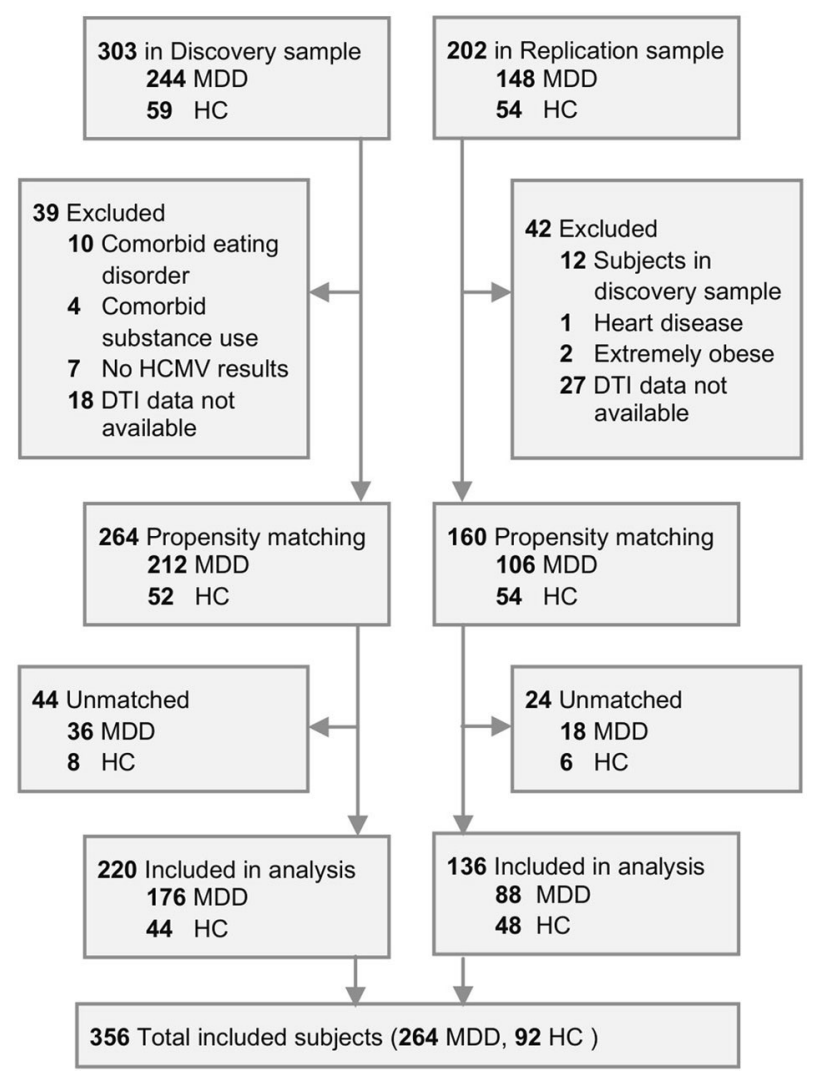

Fig. 1 Flow diagram of selection of participants. Figure shows the detailed information for final subjects' inclusion.

not differ significantly from each other. The significant cluster was selected as a region of interest (ROI) to test in the Replication sample. Lower mean FA in $\mathrm{HCMV}+$ participants with MDD compared to HCMV- participants with MDD at the same cluster was confirmed in the Replication sample (Fig. 3A and Table 2). Exploratory whole-brain voxel-wise analyses at a voxel level threshold of $p<0.05$ uncorrected, revealed lower FA in the IFOF in $\mathrm{HCMV}+$ participants with MDD compared to HCMV - participants with MDD in both the left and right hemispheres in the Discovery sample. Similar, bilaterally significant results were observed in the Replication sample participants with MDD (Fig. 3B, Table 2, and Supplementary Fig. S1). Although not statistically significant, lower FA in the bilateral IFOF was also found in $\mathrm{HCMV}+\mathrm{HC}$ participants compared to HCMV - HC participants in the Discovery sample (voxel level $p_{\text {uncorrected }}<0.05$ ) but not in the Replication sample (Supplementary Fig. S1).

In additional exploratory analyses we found that there was no significant main effect of HCMV when MDD and HC groups were combined together. Further, there was no significant main effect of diagnosis nor interaction effect of diagnosis by HCMV status in either the Discovery or the Replication samples.

Sensitivity analyses with two additional models (no covariates and eleven covariates, respectively) yielded results consistent with those reported above (Supplementary Table S4) supporting the robustness of the findings. Sensitivity analyses for unmeasured confounding suggested that the observed effect of HCMV on FA value in the right IFOF in both MDD samples was robust against unmeasured confounding. The $E$-value estimated for the right IFOF in the Discovery sample was 2.78 , indicating that in order to fully explain away the observed effect of HCMV there would need to be an unmeasured confounder that increased the likelihood of being $\mathrm{HCMV}+$ and reduced FA of the right IFOF by at least 2.78- fold each. Similarly, the E-value estimated for the effect of HCMV on the right IFOF in the Replication sample was 2.38. (Supplementary Fig. S2).

Correlations between HCMV level, CRP, and FA

Correlation analyses were performed in the HCMV+ MDD samples. There were no significant correlations between the HCMV IgG antibody level or CRP and FA in either the Discovery or Replication samples (Supplementary Fig. S3).

Associations between FA, HCMV serostatus, and specific depressive symptoms

Lower FA was associated with more sleep problems (standardized beta coefficient $(\mathrm{SBC})=-0.16,[95 \% \mathrm{Cl},-0.31$ to -0.01$]$, $\left.p_{\text {uncorrected }}<0.05\right)$ and concentration problems $(\mathrm{SBC}=-0.15$, [95\% Cl, -0.29 to 0.00$], p_{\text {uncorrected }}<0.05$ ) in participants with MDD in the Discovery sample, but not in the Replication sample (Supplementary Table S5). The results indicated that a 1 standard deviation decrease of FA was associated with a 0.16 standard deviation increase in sleep problems and 0.15 standard deviation increase in concentration problems in participants with MDD. There were no significant differences in depressive symptoms between the HCMV+ and the HCMV-MDD groups in either the Discovery or the Replication samples (Supplementary Table S6).

\section{DISCUSSION}

In this study we tested the hypothesis that HCMV would be associated with reduced white matter structural integrity in individuals with MDD. The principal finding was a bilateral reduction in FA of the IFOF in two independent groups of $\mathrm{HCMV}+$ versus HCMV - adults with MDD but no corresponding significant HCMV effect in HCs. The IFOF is a large white matter tract that connects the occipital lobe to the inferior frontal lobe (particularly the orbitofrontal cortex) via the insula and the posterolateral temporal lobe [83]. The IFOF is involved in semantic language processing [84] but perhaps more relevant to psychiatry, connects the "salience network" to the "executive network", and therefore plays a role in integrating emotional and cognitive stimuli to facilitate goal-oriented behavior $[83,85]$. Reduced FA of the IFOF has been widely reported in MDD populations [86-96] but appears to be a non-specific finding, also being reported in bipolar disorder (BD) $[89,97,98]$, outpatients with subsyndromal affective and psychotic symptoms [99], schizophrenia [100], Parkinson's disease with psychosis [101], and individuals with a history of childhood maltreatment [102]. Indeed, a meta-analysis of five different "emotional disorders" (MDD, BD, social anxiety disorder, obsessive-compulsive disorder, and post-traumatic stress disorder) reported reductions in FA in left IFOF (as well as other regions) compared to controls [103].

Nevertheless, we note that although the IFOF is the major track that passes through the ROI cluster, whole brain tractography using an averaged template suggests that other white matter fibers such as inferior longitudinal fasciculus may also pass through the ROI. Second, analysis with a more liberal statistical threshold reveals that reductions in FA may not limited to the IFOF but include the inferior longitudinal fasciculus, superior longitudinal fasciculus, and corticospinal tract (Supplementary Fig. S1). Thus, with larger sample sizes it is conceivable that a more widespread pattern of reductions in FA would be apparent. Indeed, in a previous study, we reported reduced gray matter volume (GMV) of the right orbitofrontal cortex (OFC), parahippocampal gyrus (PHG), and supramarginal gyrus (SMG) in Discovery sample participants with MDD who were $\mathrm{HCMV}+$ vs. MDD participants who were HCMV- [54]. There was a significant positive correlation between the mean FA of the ROI cluster in the IFOF and GMV of the right OFC (but not PHG or SMG) in the MDD participants of the Discovery sample (Fig. 2). These data raise the 
Table 1. Demographic characteristics of study participants after applying propensity matching.

\begin{tabular}{|c|c|c|c|c|c|c|c|c|}
\hline Discovery sample & \multicolumn{4}{|l|}{$\mathrm{HC}$} & \multicolumn{4}{|l|}{ MDD } \\
\hline$n$ & 22 & 22 & & & 88 & 88 & & \\
\hline Age (mean (SD)) & $33.50(12.27)$ & $33.09(10.43)$ & 0.91 & 0.04 & $33.07(10.18)$ & $34.92(11.14)$ & 0.25 & 0.17 \\
\hline Sex (Male (\%)) & $10(45.5)$ & $11(50.0)$ & 1.00 & 0.09 & $32(36.4)$ & $27(30.7)$ & 0.52 & 0.12 \\
\hline BMI (mean (SD)) & $27.95(5.60)$ & $30.20(5.19)$ & 0.18 & 0.42 & $29.13(5.30)$ & $28.58(5.15)$ & 0.48 & 0.11 \\
\hline Anxiety severity (mean (SD)) ${ }^{\mathrm{e}}$ & $46.98(7.73)$ & $43.66(7.38)$ & 0.15 & 0.44 & $61.90(7.03)$ & $62.74(6.34)$ & 0.41 & 0.13 \\
\hline Medicated $(\%)^{f}$ & - & - & - & - & $56(63.6)$ & $58(65.9)$ & 0.88 & 0.05 \\
\hline CTQ (mean (SD) $)^{9}$ & $32.14(6.98)$ & $35.73(12.10)$ & 0.24 & 0.36 & $45.77(16.43)$ & $47.61(20.17)$ & 0.51 & 0.10 \\
\hline Number of episodes (mean (SD) $)^{\mathrm{h}}$ & $0.00(0.00)$ & $0.00(0.00)$ & NA & 0.00 & $3.87(3.24)$ & $3.88(3.18)$ & 0.98 & 0.01 \\
\hline Alcohol use (mean (SD)) $)^{i}$ & $3.93(2.40)$ & $4.21(2.36)$ & 0.70 & 0.12 & $5.01(2.21)$ & $4.98(2.79)$ & 0.95 & 0.01 \\
\hline \multicolumn{9}{|l|}{ Replication sample } \\
\hline$n$ & 24 & 24 & & & 44 & 44 & & \\
\hline Age (mean (SD)) & $26.09(6.17)$ & $28.47(8.88)$ & 0.29 & 0.31 & $30.94(11.17)$ & $33.70(16.83)$ & 0.37 & 0.19 \\
\hline Sex (Male (\%)) & $3(12.5)$ & $3(12.5)$ & 1.00 & $<0.001$ & $10(22.7)$ & $9(20.5)$ & 1.00 & 0.06 \\
\hline BMI (mean (SD)) & $23.65(4.95)$ & $25.90(5.02)$ & 0.13 & 0.45 & $26.86(4.84)$ & $28.88(5.74)$ & 0.08 & 0.38 \\
\hline Education (mean (SD)) & $6.75(1.33)$ & $6.92(1.35)$ & 0.67 & 0.13 & $6.57(1.70)$ & $6.23(1.65)$ & 0.34 & 0.20 \\
\hline Depression severity (mean (SD)) & $43.58(5.27)$ & $43.65(6.50)$ & 0.97 & 0.01 & $62.65(6.51)$ & $62.41(6.87)$ & 0.87 & 0.04 \\
\hline Anxiety severity (mean (SD)) & $46.80(5.94)$ & $45.74(8.65)$ & 0.62 & 0.14 & $63.07(6.48)$ & $63.35(5.67)$ & 0.83 & 0.05 \\
\hline Medicated (\%) & - & - & - & - & $13(29.5)$ & $10(22.7)$ & 0.63 & 0.16 \\
\hline CTQ (mean (SD)) & $31.00(5.42)$ & $34.21(11.68)$ & 0.23 & 0.35 & $47.09(16.19)$ & $51.80(19.98)$ & 0.23 & 0.26 \\
\hline Number of episodes (mean (SD)) & $0.00(0.00)$ & $0.00(0.00)$ & NA & 0.00 & $3.91(3.43)$ & $4.37(3.46)$ & 0.53 & 0.13 \\
\hline
\end{tabular}

$M D D$ major depressive disorder, $H C$ healthy control, HCMV human cytomegalovirus, HCMV - human cytomegalovirus seronegative, HCMV + human cytomegalovirus seropositive, SMD standardized mean difference, $B M I$ body mass index, CTQ childhood trauma questionnaire, CRP C-reactive protein ${ }^{a}$ Calculated using $X^{2}$ test for categorical variables and two-tailed $t$-test for continuous variables.

${ }^{\mathrm{b}}$ The standardized mean differences less than 0.1 reveals a negligible imbalance.

'Measured by ordered categories. Full categories see Supplementary Table S7.

dPROMIS depression $T$-score was used.

ePROMIS anxiety $T$-score was used.

${ }^{f}$ Medicated defined as patients with MDD taking psychotropic medication.

${ }^{9}$ Childhood trauma questionnaire total score was used.

${ }^{\mathrm{h}}$ Measured by MINI interview. Participants with over ten episodes were treated as having had ten episodes.

'Log-transformed lifetime alcohol usage were used. Data obtained from CDDR interview.

${ }^{\mathrm{j} H C M V}$ IgG level $z$-score was used.

${ }^{\mathrm{k}} \mathrm{CRP}$ concentration (log transformed).

'Average absolute volume to volume head motion $(\mathrm{mm})$ in the scanner was used.

possibility that HCMV may alter the structure of a neural circuit involving the OFC. The OFC is involved in reward processing, decision making, and the regulation of negative affect [104, 105] and has been reported to be reduced in volume or thickness in large consortia studies and meta-analyses of MDD populations [106-108].

A steeper decline in OFC volumes during adolescence has been associated with anhedonia [109] and smaller OFC volumes and reduced $F A$ in several tracts including the IFOF were recently shown to be associated with higher polygenic risk scores for anhedonia [110]. However, here we did not observe a significant relationship between mean FA in the IFOF ROI and anhedonia as measured by the first item of the PHQ-9. Rather, lower FA of the IFOF was associated with greater sleep and concentration problems in the MDD participants of the Discovery sample (Table S5) but these relationships were not significant in the Replication sample and should therefore be treated with caution. Moreover, exploratory analyses to determine if specific clusters of depressive symptoms were associated with HCMV infection yielded non-significant results (Table S6). Thus, at least in terms of the psychometric instruments administered in this study, $\mathrm{HCMV}+$ and $\mathrm{HCMV}$ - participants with MDD do not show clear differences in depressive symptomatology. 

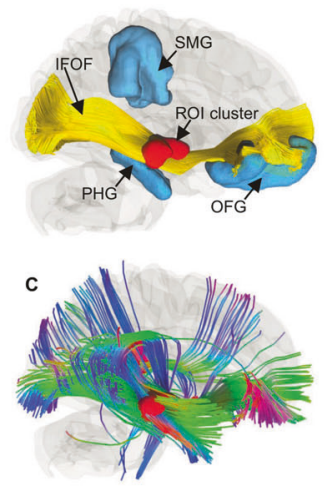

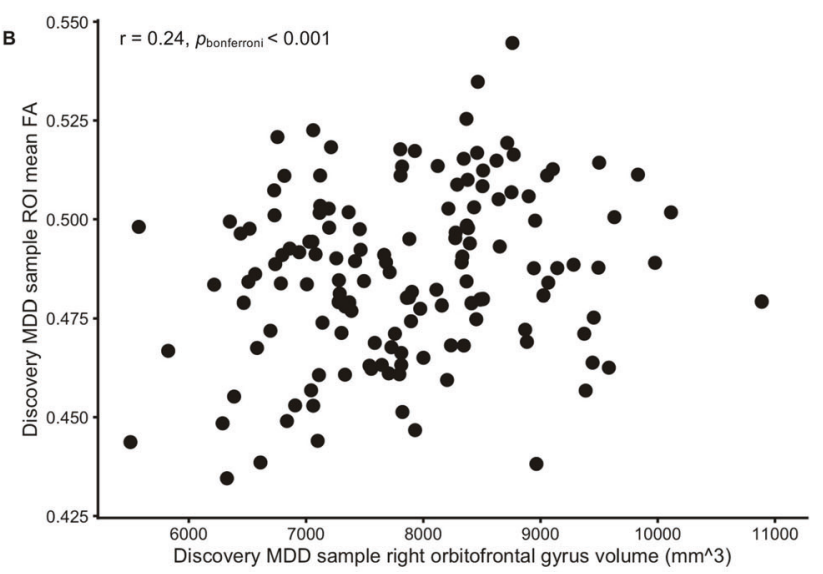

Fig. 2 Illustration of the white matter fiber tract associated with HCMV infection. A The red region of interest (ROI) was determined by the clusters showing significantly lower FA ( $p F W E<0.05$ ) in HCMV+ participants with MDD compared to HCMV-participants with MDD in the Discovery sample. A population-averaged tractography atlas $(N=842)$ was used to identify the right inferior fronto-occipital fasciculus (IFOF), which passes $100 \%$ through the ROI cluster. Interestingly, three right hemisphere gray matter regions, the orbitofrontal gyrus (OFG), the parahippocampal gyrus (PHG) and the supramarginal gyrus (SMG) showed reduced volume in HCMV+ participants with MDD compared to HCMV - participants with MDD in the Discovery sample (previously published in the ref. [54]). B There was a significant positive association $\left(r=0.24, p_{\text {bonferroni }}<0.001\right)$ between the mean FA from the ROI and the orbitofrontal gyrus volume in Discovery MDD sample (gray matter volume data from the ref. [54]). This association was also significant after regressing out age, sex, BMI, and total intracranial volume (standardized beta coefficient $=0.20$, $[95 \% \mathrm{Cl}, 0.08-0.31], P=0.001$ ). No significant associations were found with the PHG and the SMG. C Illustration of putative connections between the ROI and other brain regions. A deterministic fiber-tracking was performed using a published population-average template (HCP-842 template). Tractography was conducted using the DSI Studio with default parameter setting, and 50,000 seeding regions (starting points) were placed across the whole brain. The same cluster identified from the Discovery sample was used as the region of interest (ROI), which was used to "filter in" the tracks that passed through this region. A total of 829 tracts that passing through ROI was identified and shown in C. Although IFOF is the major track that passes through the ROI cluster, whole brain tractography suggest that the ROI may connect with the temporal lobe, parietal lobe, and prefrontal cortex via other pathways such as the inferior longitudinal fasciculus and the superior longitudinal fasciculus. Thus, it is important to note that the effect of HCMV may not be localized in IFOF.

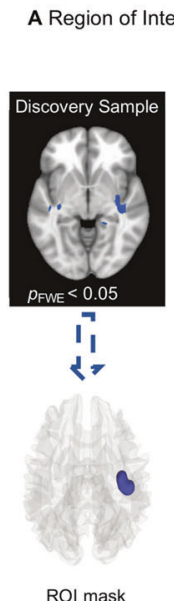

ROI mask
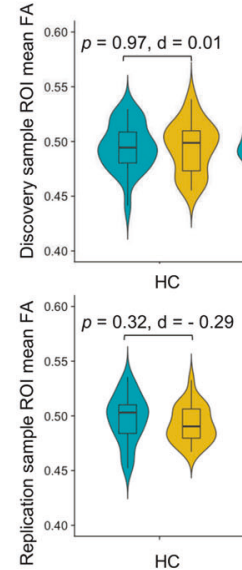

$d=-0.29$

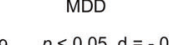

$p_{F W E}<0.05, d=-0.58$

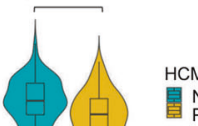

Negative

Positive

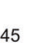

0.45

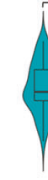

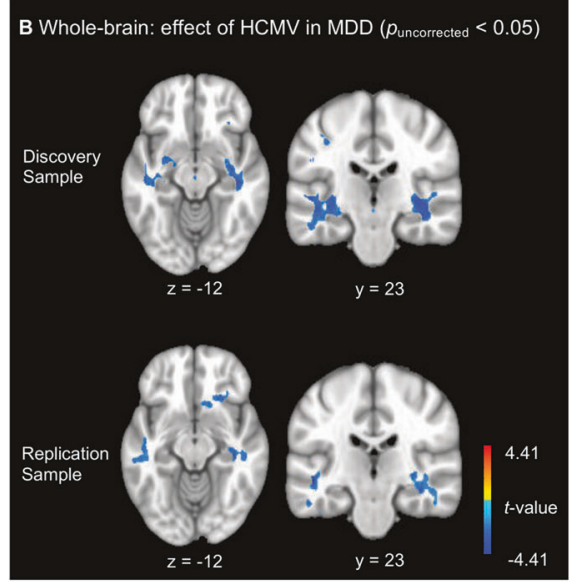

MDD

Fig. 3 HCMV seropositive participants with MDD exhibited significantly lower white matter fractional anisotropy in both samples. A In the Discovery sample, significantly lower FA $\left(p_{\mathrm{FWE}}<0.05\right)$ was observed in the right inferior fronto-occipital fasciculus in HCMV+ participants with MDD compared to HCMV - participants with MDD. Significantly lower mean FA in HCMV + participants with MDD compared to HCMV participants with MDD at the same cluster was confirmed in the Replication sample. Cohen's $d$ was calculated after regressing out age, sex and BMI. B Exploratory whole-brain voxel-wise analyses using a voxel level threshold of $p_{\text {uncorrected }}<0.05$ revealed the HCMV effect in MDD was bilateral in both samples.

The mechanism underlying the link between HCMV infection and reduced FA is unclear. Because HCMV is neurotrophic [23-26], viral reactivation could, in theory, damage the brain directly or elicit a microglia-mediated antiviral immune response that has detrimental effects on brain tissue. Multifocal lesions of the deep white matter are commonly detected with MRI in children with congenital HCMV infection [111-113] while
T2-weighted periventricular hyperintensities are characteristic of HIV patients with HCMV encephalitis $[114,115]$. Clearly these lesions are not specific to the IFOF, although the only DTI study of which we are aware did report reduced FA in white matter tracts of the occipital lobe in neonates with a postnatallyacquired HCMV infection [116]. Another mechanism through which HCMV infection may lead to microstructural changes in 
Table 2. Brain regions showing significant differences in white matter FA between HCMV+ participants with MDD and HCMV - participants with MDD.

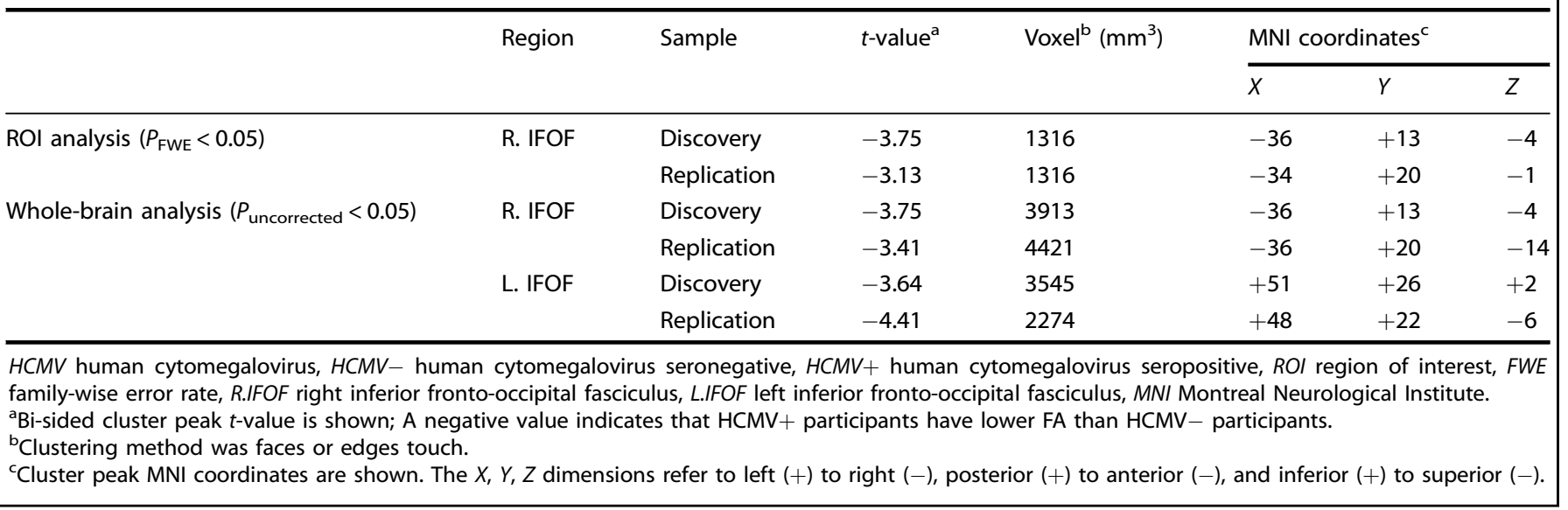

white matter is via systemic inflammation including the longterm accumulation of cytotoxic $\mathrm{CD}^{2} 8^{-}$T-cells [36]. Indeed, reduced white matter integrity (including FA of the IFOF) of both MDD [93] and BD [117] participants has been previously associated with increased serum pro-inflammatory cytokine concentrations. Negative correlations between FA and circulating inflammatory mediators have also been reported in schizophrenia [118], Alzheimer's disease [119], and healthy adults $[120,121]$. In this regard, the absence of a significant correlation between CRP and FA in the current study was unexpected. It is conceivable that CRP does not adequately capture this brain-immune relationship, since the aforementioned studies reported associations between FA and inflammatory cytokines rather than CRP. Specific markers of viral infection such as CXCL10/IP-10 or macrophage activation such as SCD14 may also be more sensitive to HCMV reactivation than CRP [122]. Another possibility is that that the single time point at which CRP was measured did not always overlap with viral shedding since the two studies were not designed to enroll participants with an active HCMV infection.

We did not find a significant association between HCMV IgG level and FA. Leboyer and colleagues reported an inverse correlation between HCMV lgG level and right hippocampal volumes in patients with schizophrenia and BD [123], and in the Discovery sample we recently reported a similar relationship between HCMV infection and GMV of the right orbitofrontal gyrus and right PHG [54], which are located adjacent to the IFOF (Fig. 2). However, IgG antibody titer only provides an approximate measure of HCMV shedding since IgG antibodies have a half-life of $<30$ days and are also influenced by host factors. Thus, the signal-to-noise ratio of these correlational analyses are likely to be low.

Because of the cross-sectional design we cannot conclude that HCMV is the cause of the reduction in FA since an unknown causal factor may co-occur with HCMV infection. Nevertheless, we attempted to mitigate confounding bias through two strategies. First, we matched $\mathrm{HCMV}+$ and $\mathrm{HCMV}$ - groups on the basis of ten potential confounders. Second, the statistical models further adjusted for all the measured confounders in the sensitivity analyses. Thus, any imbalances that remained after the matching process were controlled for by the statistical analysis. In particular, we attempted to match the groups on childhood trauma which we previously found to be more prevalent in $\mathrm{HCMV}+$ individuals with MDD [124] as well as education level, a surrogate marker for childhood socioeconomic status [125]. Both childhood trauma and socioeconomic status have previously been associated with reductions in white matter integrity $[102,126]$. However, it is important to acknowledge that we could not directly control for childhood socioeconomic status. We computed E-values to estimate the magnitude of the effect an unmeasured confounding factor(s) would need to have in order to explain away the HCMV effect. The estimated E-value was much greater than the magnitude of the effect of the largest known confounder, i.e., age, indicating that the HCMV effect observed in current study is unlikely to be easily eliminated by further inclusion of confounders.

Notwithstanding the caveats in drawing causal conclusions about HCMV, our results raise the possibility that periodic reactivation of the virus may negatively affect brain structure, thus contributing to the emergence or maintenance of depressive symptoms. Conceivably, FDA-approved medications for the treatment of HCMV such as valganciclovir or letermovir $[55,127-129]$ may have therapeutic or prophylactic effects in a subgroup of patients. A clinical trial in HIV patients demonstrated that 8 weeks of anti-HCMV therapy with valganciclovir reduced CD8 + cell activation and CRP, sCD14, and TNFR2 concentrations by $\sim 1$ quartile, an effect that persisted for at least 4 weeks after valganciclovir discontinuation [130]. Testing whether an immunemodulating effect of anti-HCMV medication could modify brain structure and/or reduce depressive symptoms in the context of MDD is indicated.

Several limitations deserve mention. Although we did not observe a significant main effect of diagnosis or interaction effect on FA, these results should be interpreted with caution. The current study was not designed to investigate the effect of depression on FA. That is, the propensity matching focused on HCMV status, not diagnosis, and further, the small sample size of the $\mathrm{HC}$ groups limited the statistical power available to detect a main effect of diagnosis and an interaction effect. Second, the cross-sectional design did not allow us to differentiate between possible acute and cumulative effects of HCMV on brain structure. Third, it is conceivable that other viral infections that co-occur with HCMV may have accounted for the reductions in FA. Nevertheless, HCMV is more strongly linked with congenital brain abnormalities than other herpesviruses and recurrent HCMV reactivation disrupts the balance of the immune system to a greater extent than other herpesviruses [131]. Finally, while FA is usually considered to be a general measure of microstructural integrity of the white matter, reductions in FA are multifactorial $[60,132,133]$. Thus, the biological correlates of the 
changes in FA associated with CMV infection are unclear and are not necessarily reflective of a neuropathological process.

In sum, after careful balancing of $\mathrm{HCMV}+$ and $\mathrm{HCMV}$ - groups for ten baseline demographic and clinical variables to minimize confounding bias, we found evidence for an HCMV-associated reduction in FA of the IFOF in two independent MDD samples. While causal conclusions cannot be drawn from these crosssectional analyses, the results offer a new perspective on the origin of structural brain abnormalities in a HCMV + subgroup of patients with MDD. They also potentially open-up new avenues of treatment given the availability of anti-HCMV medications.

\section{FUNDING AND DISCLOSURE}

This work was supported by The William K. Warren Foundation, the National Institute of Mental Health (R21MH11387), and the National Institute of General Medical Sciences (P20GM121312). The funding sources had no role in the design and conduct of the study: collection, management, analysis, and interpretation of the data; preparation, review, or approval of the manuscript; and decision to submit the manuscript for publication.

Dr. Hunt receives support from Merck (donated drug) for a clinical trial of letermovir. Dr. Paulus is an advisor to Spring Care, Inc., a behavioral health startup, he has received royalties for an article about methamphetamine in UpToDate. All other authors, including members of Tulsa 1000 Investigators, have no disclosures to report.

\section{DATA AVAILABILITY}

The full preprocessing script, statistical analysis code, and unthresholded statistical imaging maps are available from the corresponding author on reasonable request.

\section{ACKNOWLEDGEMENTS}

The authors thank all the research participants and wish to acknowledge the contributions of Brenda Davis, Debbie Neal, Chibing Tan, and Ashlee Taylor from the laboratory of TKT towards the transport, processing, and handling of all blood samples.

\section{AUTHOR CONTRIBUTIONS}

Conception and design of work: HZ, JS. Data acquisition: BNF, JB, KB, T1000 Investigators, TKT, RHY, MPP, and JS. Data analysis: HZ, MB, and RK. Interpretation of results: HZ, MRI, RHY, MPP, and JS. Drafting manuscript: $H Z$, JS, Revision of manuscript: $H Z, M B, B N F, R K, F C Y, J B, K B, T 1000$ Investigators, PWH, TKT, MRI RHY, MPP, and JS. Funding: MPP, JS.

\section{ADDITIONAL INFORMATION}

Supplementary information The online version contains supplementary material available at https://doi.org/10.1038/s41386-021-00971-1.

Publisher's note Springer Nature remains neutral with regard to jurisdictional claims in published maps and institutional affiliations.

\section{REFERENCES}

1. Miller $\mathrm{AH}$, Raison $\mathrm{CL}$. The role of inflammation in depression: from evolutionary imperative to modern treatment target. Nat Rev Immunol. 2016;16:22-34.

2. Dantzer R, O'Connor JC, Freund GG, Johnson RW, Kelley KW. From inflammation to sickness and depression: when the immune system subjugates the brain. Nat Rev Neurosci. 2008;9:46-56.

3. Mechawar N, Savitz J. Neuropathology of mood disorders: do we see the stigmata of inflammation? Transl Psychiatry. 2016;6:e946.

4. Chiang JJ, Cole SW, Bower JE, Irwin MR, Taylor SE, Arevalo J, et al. Depressive symptoms and immune transcriptional profiles in late adolescents. Brain Behav Immun. 2019;80:163-169.
5. Cole SW, Levine ME, Arevalo JM, Ma J, Weir DR, Crimmins EM. Loneliness, eudaimonia, and the human conserved transcriptional response to adversity. Psychoneuroendocrinology 2015;62:11-7.

6. Cole SW. Human social genomics. PLoS Genet. 2014;10:e1004601.

7. Leday GGR, Vertes PE, Richardson S, Greene JR, Regan T, Khan S, et al. Replicable and coupled changes in innate and adaptive immune gene expression in two case-control studies of blood microarrays in major depressive disorder. Biol Psychiatry. 2018;83:70-80.

8. Zorrilla EP, Luborsky L, McKay JR, Rosenthal R, Houldin A, Tax A, et al. The relationship of depression and stressors to immunological assays: a metaanalytic review. Brain Behav Immun. 2001;15:199-226.

9. Herbert TB, Cohen S. Depression and immunity: a meta-analytic review. Psychol Bull. 1993;113:472-86.

10. Cohen S, Janicki-Deverts D, Doyle WJ, Miller GE, Frank E, Rabin BS, et al. Chronic stress, glucocorticoid receptor resistance, inflammation, and disease risk. Proc Natl Acad Sci USA. 2012;109:5995-9.

11. Cohen S, Doyle WJ, Skoner DP. Psychological stress, cytokine production, and severity of upper respiratory illness. Psychosom Med. 1999;61:175-80.

12. Marsland AL, Bachen EA, Cohen S, Rabin B, Manuck SB. Stress, immune reactivity and susceptibility to infectious disease. Physiol Behav. 2002;77:711-6.

13. LeRoy AS, Murdock KW, Jaremka LM, Loya A, Fagundes CP. Loneliness predicts self-reported cold symptoms after a viral challenge. Health Psychol. 2017;36:512-20.

14. Irwin MR, Levin MJ, Carrillo C, Olmstead R, Lucko A, Lang N, et al. Major depressive disorder and immunity to varicella-zoster virus in the elderly. Brain Behav Immun. 2011;25:759-66.

15. Irwin MR, Levin MJ, Laudenslager ML, Olmstead R, Lucko A, Lang N, et al. Varicella zoster virus-specific immune responses to a herpes zoster vaccine in elderly recipients with major depression and the impact of antidepressant medications. Clin Infect Dis. 2013;56:1085-93.

16. Afsar B, Elsurer R, Eyileten T, Yilmaz MI, Caglar K. Antibody response following hepatitis $B$ vaccination in dialysis patients: does depression and life quality matter? Vaccine 2009;27:5865-9.

17. Ford BN, Yolken RH, Dickerson FB, Teague TK, Irwin MR, Paulus MP, et al. Reduced immunity to measles in adults with major depressive disorder. Psychol Med. 2018;49:1-7.

18. Evans DL, Ten Have TR, Douglas SD, Gettes DR, Morrison M, Chiappini MS, et al. Association of depression with viral load, CD8 T lymphocytes, and natural killer cells in women with HIV infection. Am J Psychiatry. 2002;159:1752-9.

19. Leserman J, Petitto JM, Perkins DO, Folds JD, Golden RN, Evans DL. Severe stress, depressive symptoms, and changes in lymphocyte subsets in human immunodeficiency virus-infected men. A 2-year follow-up study. Arch Gen Psychiatry. 1997;54:279-85.

20. Leserman J. HIV disease progression: depression, stress, and possible mechanisms. Biol Psychiatry. 2003;54:295-306.

21. Picarda G, Benedict CA. Cytomegalovirus: shape-shifting the immune system. J Immunol. 2018;200:3881-89.

22. Brune W, Andoniou CE. Die another day: inhibition of cell death pathways by cytomegalovirus. Viruses. 2017;9:249.

23. Alcendor DJ, Charest AM, Zhu WQ, Vigil HE, Knobel SM. Infection and upregulation of proinflammatory cytokines in human brain vascular pericytes by human cytomegalovirus. J Neuroinflammation. 2012;9:95.

24. Poland SD, Costello P, Dekaban GA, Rice GP. Cytomegalovirus in the brain: in vitro infection of human brain-derived cells. J Infect Dis. 1990;162:1252-62.

25. Tsutsui Y, Kosugi I, Kawasaki H. Neuropathogenesis in cytomegalovirus infection: indication of the mechanisms using mouse models. Rev Med Virol. 2005;15:327-45.

26. van Den Pol AN, Mocarski E, Saederup N, Vieira J, Meier TJ. Cytomegalovirus cell tropism, replication, and gene transfer in brain. J Neurosci. 1999;19:10948-65.

27. Bosnjak VM, Dakovic I, Duranovic V, Lujic L, Krakar G, Marn B. Malformations of cortical development in children with congenital cytomegalovirus infection-a study of nine children with proven congenital cytomegalovirus infection. Coll Antropol. 2011;35:229-34.

28. Manicklal S, Emery VC, Lazzarotto T, Boppana SB, Gupta RK. The "silent" global burden of congenital cytomegalovirus. Clin Microbiol Rev. 2013;26:86-102.

29. Brecht KF, Goelz R, Bevot A, Krageloh-Mann I, Wilke M, Lidzba K. Postnatal human cytomegalovirus infection in preterm infants has long-term neuropsychological sequelae. J Pediatr. 2015;166:834-9.

30. Prosch S, Wendt CE, Reinke P, Priemer C, Oppert M, Kruger DH, et al. A novel link between stress and human cytomegalovirus (HCMV) infection: sympathetic hyperactivity stimulates HCMV activation. Virology 2000;272:357-65.

31. Glaser R, Kiecolt-Glaser JK, Speicher CE, Holliday JE. Stress, loneliness, and changes in herpesvirus latency. J Behav Med. 1985;8:249-60. 
32. Sarid O, Anson O, Yaari A, Margalith M. Academic stress, immunological reaction, and academic performance among students of nursing and physiotherapy. Res Nurs Health. 2004;27:370-7.

33. Mehta SK, Stowe RP, Feiveson AH, Tyring SK, Pierson DL. Reactivation and shedding of cytomegalovirus in astronauts during spaceflight. J Infect Dis. 2000;182:1761-4.

34. Mehta SK, Laudenslager ML, Stowe RP, Crucian BE, Sams CF, Pierson DL. Multiple latent viruses reactivate in astronauts during Space Shuttle missions. Brain Behav Immun. 2014;41:210-7.

35. Pariante CM, Carpiniello B, Orru MG, Sitzia R, Piras A, Farci AM, et al. Chronic caregiving stress alters peripheral blood immune parameters: the role of age and severity of stress. Psychother Psychosom. 1997;66:199-207.

36. Bano A, Pera A, Almoukayed A, Clarke THS, Kirmani S, Davies KA, et al. CD28 (null) CD4 T-cell expansions in autoimmune disease suggest a link with cytomegalovirus infection. F1000Res. 2019;8.

37. Limaye AP, Kirby KA, Rubenfeld GD, Leisenring WM, Bulger EM, Neff MJ, et al. Cytomegalovirus reactivation in critically ill immunocompetent patients. Jama 2008;300:413-22

38. Zivadinov R, Chin J, Horakova D, Bergsland N, Weinstock-Guttman B, TamanoBlanco $M$, et al. Humoral responses to herpesviruses are associated with neurodegeneration after a demyelinating event: results from the multi-center set study. J Neuroimmunol. 2014;273:58-64.

39. Lurain NS, Hanson BA, Martinson J, Leurgans SE, Landay AL, Bennett DA, et al. Virological and immunological characteristics of human cytomegalovirus infection associated with Alzheimer disease. J Infect Dis. 2013;208:564-72.

40. Appels A, Bar FW, Bar J, Bruggeman C, de Baets M. Inflammation, depressive symptomtology, and coronary artery disease. Psychosom Med. 2000;62:601-5.

41. Rector JL, Dowd JB, Loerbroks A, Burns VE, Moss PA, Jarczok MN, et al. Consistent associations between measures of psychological stress and CMV antibody levels in a large occupational sample. Brain Behav Immun. 2014;38:133-41.

42. Miller GE, Freedland KE, Duntley S, Carney RM. Relation of depressive symptoms to $C$-reactive protein and pathogen burden (cytomegalovirus, herpes simplex virus, Epstein-Barr virus) in patients with earlier acute coronary syndromes. Am J Cardiol. 2005;95:317-21.

43. Dickerson F, Wilcox HC, Adamos M, Katsafanas E, Khushalani S, Origoni A, et al. Suicide attempts and markers of immune response in individuals with serious mental illness. J Psychiatr Res. 2017;87:37-43.

44. Simanek AM, Cheng C, Yolken R, Uddin M, Galea S, Aiello AE. Herpesviruses, inflammatory markers and incident depression in a longitudinal study of Detroit residents. Psychoneuroendocrinology 2014;50:139-48.

45. Burgdorf KS, Trabjerg BB, Pedersen MG, Nissen J, Banasik K, Pedersen OB, et al. Large-scale study of Toxoplasma and Cytomegalovirus shows an association between infection and serious psychiatric disorders. Brain Behav Immun. 2019;79:152-8.

46. Frye MA, Coombes BJ, McElroy SL, Jones-Brando L, Bond DJ, Veldic M, et al. Association of cytomegalovirus and Toxoplasma gondii antibody titers with bipolar disorder. JAMA Psychiatry. 2019;76:1285-93.

47. Simanek AM, Zheng C, Yolken R, Haan M, Aiello AE. A Longitudinal study of the association between persistent pathogens and incident depression among older U.S. Latinos. J Gerontol A. 2019;74:634-41.

48. Dickerson F, Origoni A, Schweinfurth LAB, Stallings C, Savage CLG, Sweeney K, et al. Clinical and serological predictors of suicide in schizophrenia and major mood disorders. J Nerv Ment Dis. 2018:206:173-8.

49. Jaremka LM, Fagundes CP, Glaser R, Bennett JM, Malarkey WB, Kiecolt-Glaser JK. Loneliness predicts pain, depression, and fatigue: understanding the role of immune dysregulation. Psychoneuroendocrinology 2013;38:1310-7.

50. Prossin AR, Yolken $\mathrm{RH}$, Kamali $\mathrm{M}$, Heitzeg $\mathrm{MM}$, Kaplow JB, Coryell $\mathrm{WH}$, et al. Cytomegalovirus antibody elevation in bipolar disorder: relation to elevated mood states. Neural Plast. 2015;2015:939780.

51. Phillips AC, Carroll D, Khan N, Moss P. Cytomegalovirus is associated with depression and anxiety in older adults. Brain Behav Immun. 2008;22:52-5.

52. Trzonkowski P, Mysliwska J, Godlewska B, Szmit E, Lukaszuk K, Wieckiewicz J, et al. Immune consequences of the spontaneous pro-inflammatory status in depressed elderly patients. Brain Behav Immun. 2004;18:135-48.

53. Coryell W, Wilcox H, Evans SJ, Pandey GN, Jones-Brando L, Dickerson F, et al. Latent infection, inflammatory markers and suicide attempt history in depressive disorders. J Affect Disord. 2020;270:97-101.

54. Zheng $H$, Ford BN, Bergamino $M$, Kuplicki $R$, Investigators $T$, Hunt $P W$, et al. A hidden menace? Cytomegalovirus infection is associated with reduced cortical gray matter volume in major depressive disorder. Mol Psychiatry. 2020.

55. Marty FM, Ljungman P, Chemaly RF, Maertens J, Dadwal SS, Duarte RF, et al. Letermovir prophylaxis for cytomegalovirus in hematopoietic-cell transplantation. N Engl J Med. 2017;377:2433-44.
56. Plotkin SA, Boppana SB. Vaccination against the human cytomegalovirus. Vaccine 2018;37:7437-42.

57. Cumberworth SL, Barrie JA, Cunningham ME, de Figueiredo DPG, Schultz V, Wilder-Smith AJ, et al. Zika virus tropism and interactions in myelinating neural cell cultures: CNS cells and myelin are preferentially affected. Acta Neuropathol Commun. 2017;5:50.

58. Liu H, Liu J, Xu E, Tu G, Guo M, Liang S, et al. Human immunodeficiency virus protein Tat induces oligodendrocyte injury by enhancing outward $\mathrm{K}(+)$ current conducted by KV1.3. Neurobiol Dis. 2017;97:1-10.

59. Czeh B, Nagy SA. Clinical findings documenting cellular and molecular abnormalities of glia in depressive disorders. Front Mol Neurosci. 2018;11:56.

60. Chang EH, Argyelan M, Aggarwal M, Chandon TS, Karlsgodt KH, Mori S, et al. The role of myelination in measures of white matter integrity: combination of diffusion tensor imaging and two-photon microscopy of CLARITY intact brains. Neuroimage 2017;147:253-61.

61. Cerina $M$, Muthuraman $M$, Gallus $M$, Koirala N, Dik A, Wachsmuth $L$, et al. Myelination- and immune-mediated MR-based brain network correlates. J Neuroinflammation. 2020;17:186.

62. Beaulieu C. The basis of anisotropic water diffusion in the nervous system - a technical review. NMR Biomed. 2002;15:435-55.

63. Sheehan DV, Lecrubier Y, Sheehan KH, Amorim P, Janavs J, Weiller E, et al. The Mini-International Neuropsychiatric Interview (M.I.N.I.): the development and validation of a structured diagnostic psychiatric interview for DSM-IV and ICD10. J Clin Psychiatry. 1998;59:22-33.

64. Gershon RC, Rothrock N, Hanrahan R, Bass M, Cella D. The use of PROMIS and assessment center to deliver patient-reported outcome measures in clinical research. J Appl Meas. 2010;11:304-14.

65. Kroenke K, Spitzer RL, Williams JB. The PHQ-9: validity of a brief depression severity measure. J Gen Intern Med. 2001;16:606-13.

66. Brown SA, Myers MG, Lippke L, Tapert SF, Stewart DG, Vik PW. Psychometric evaluation of the Customary Drinking and Drug Use Record (CDDR): a measure of adolescent alcohol and drug involvement. J Stud Alcohol. 1998;59:427-38.

67. Bernstein DP, Stein JA, Newcomb MD, Walker E, Pogge D, Ahluvalia T, et al. Development and validation of a brief screening version of the Childhood Trauma Questionnaire. Child Abus Negl. 2003;27:169-90.

68. Victor TA, Khalsa SS, Simmons WK, Feinstein JS, Savitz J, Aupperle RL, et al. Tulsa 1000: a naturalistic study protocol for multilevel assessment and outcome prediction in a large psychiatric sample. BMJ Open. 2018;8:e016620.

69. Andersson JLR, Sotiropoulos SN. An integrated approach to correction for offresonance effects and subject movement in diffusion MR imaging. Neuroimage 2016;125:1063-78.

70. Bastiani M, Cottaar M, Fitzgibbon SP, Suri S, Alfaro-Almagro F, Sotiropoulos SN, et al. Automated quality control for within and between studies diffusion MRI data using a non-parametric framework for movement and distortion correction. Neuroimage 2019;184:801-12.

71. Andersson JLR, Graham MS, Zsoldos E, Sotiropoulos SN. Incorporating outlier detection and replacement into a non-parametric framework for movement and distortion correction of diffusion MR images. Neuroimage 2016;141:556-72.

72. Smith SM. Fast robust automated brain extraction. Hum Brain Mapp. 2002;17:143-55.

73. Behrens TE, Woolrich MW, Jenkinson M, Johansen-Berg $H$, Nunes RG, Clare $S$, et al. Characterization and propagation of uncertainty in diffusion-weighted MR imaging. Magn Reson Med. 2003;50:1077-88.

74. Avants BB, Epstein CL, Grossman M, Gee JC. Symmetric diffeomorphic image registration with cross-correlation: evaluating automated labeling of elderly and neurodegenerative brain. Med Image Anal. 2008;12:26-41.

75. Smith SM, Jenkinson M, Woolrich MW, Beckmann CF, Behrens TE, Johansen-Berg $\mathrm{H}$, et al. Advances in functional and structural MR image analysis and implementation as FSL. Neuroimage 2004;23:S208-19.

76. VanderWeele TJ. Principles of confounder selection. Eur J Epidemiol. 2019;34:211-19.

77. Chen G, Adleman NE, Saad ZS, Leibenluft E, Cox RW. Applications of multivariate modeling to neuroimaging group analysis: a comprehensive alternative to univariate general linear model. Neuroimage 2014;99:571-88.

78. Austin PC. An introduction to propensity score methods for reducing the effects of confounding in observational studies. Multivar Behav Res. 2011:46:399-424.

79. Forman SD, Cohen JD, Fitzgerald M, Eddy WF, Mintun MA, Noll DC. Improved assessment of significant activation in functional magnetic resonance imaging (fMRI): use of a cluster-size threshold. Magn Reson Med. 1995;33:636-47.

80. Cox RW, Chen G, Glen DR, Reynolds RC, Taylor PA. fMRI clustering and falsepositive rates. Proc Natl Acad Sci USA. 2017;114:E3370-E71.

81. Yeh FC, Panesar S, Fernandes D, Meola A, Yoshino M, Fernandez-Miranda JC, et al. Population-averaged atlas of the macroscale human structural connectome and its network topology. Neuroimage 2018;178:57-68. 
82. VanderWeele TJ, Ding P. Sensitivity analysis in observational research: introducing the E-value. Ann Intern Med. 2017;167:268-74.

83. Conner AK, Briggs RG, Sali G, Rahimi M, Baker CM, Burks JD, et al. A connectomic atlas of the human cerebrum-chapter 13: tractographic description of the inferior fronto-occipital fasciculus. Oper Neurosurg. 2018;15:S436-S43.

84. Almairac F, Herbet G, Moritz-Gasser S, de Champfleur NM, Duffau $H$. The left inferior fronto-occipital fasciculus subserves language semantics: a multilevel lesion study. Brain Struct Funct. 2015;220:1983-95.

85. Waller R, Dotterer HL, Murray L, Maxwell AM, Hyde LW. White-matter tract abnormalities and antisocial behavior: a systematic review of diffusion tensor imaging studies across development. Neuroimage Clin. 2017;14:201-15.

86. Versace A, Almeida JR, Quevedo K, Thompson WK, Terwilliger RA, Hassel S, et al. Right orbitofrontal corticolimbic and left corticocortical white matter connectivity differentiate bipolar and unipolar depression. Biol Psychiatry. 2010;68:560-7.

87. Ota M, Noda T, Sato N, Hattori K, Hori H, Sasayama D, et al. White matter abnormalities in major depressive disorder with melancholic and atypical features: a diffusion tensor imaging study. Psychiatry Clin Neurosci. 2015;69:360-8.

88. Bessette KL, Nave AM, Caprihan A, Stevens MC. White matter abnormalities in adolescents with major depressive disorder. Brain Imaging Behav. 2014;8:531-41.

89. Wei S, Womer FY, Edmiston EK, Zhang R, Jiang $\mathrm{X}, \mathrm{Wu} F$, et al. Structural alterations associated with suicide attempts in major depressive disorder and bipolar disorder: a diffusion tensor imaging study. Prog Neuropsychopharmacol Biol Psychiatry. 2020;98:109827.

90. Liao Y, Huang X, Wu Q, Yang C, Kuang W, Du M, et al. Is depression a disconnection syndrome? Meta-analysis of diffusion tensor imaging studies in patients with MDD. J Psychiatry Neurosci. 2013;38:49-56.

91. Lai $\mathrm{CH}, \mathrm{Wu} \mathrm{YT}$. The white matter microintegrity alterations of neocortical and limbic association fibers in major depressive disorder and panic disorder: the comparison. Medicine. 2016;95:e2982.

92. Liu X, Watanabe K, Kakeda S, Yoshimura R, Abe O, Ide S, et al. Relationship between white matter integrity and serum cortisol levels in drug-naive patients with major depressive disorder: diffusion tensor imaging study using tractbased spatial statistics. Br J Psychiatry. 2016;208:585-90.

93. Sugimoto K, Kakeda S, Watanabe K, Katsuki A, Ueda I, Igata N, et al. Relationship between white matter integrity and serum inflammatory cytokine levels in drug-naive patients with major depressive disorder: diffusion tensor imaging study using tract-based spatial statistics. Transl Psychiatry. 2018;8:141.

94. Cheng Y, Xu J, Yu H, Nie B, Li N, Luo C, et al. Delineation of early and later adult onset depression by diffusion tensor imaging. PLoS ONE. 2014;9:e112307.

95. Bergamino $M$, Kuplicki R, Victor TA, Cha YH, Paulus MP. Comparison of two different analysis approaches for DTI free-water corrected and uncorrected maps in the study of white matter microstructural integrity in individuals with depression. Hum Brain Mapp. 2017;38:4690-702.

96. Bergamino M, Pasternak O, Farmer M, Shenton ME, Hamilton JP. Applying a free-water correction to diffusion imaging data uncovers stress-related neural pathology in depression. Neuroimage Clin. 2016;10:336-42.

97. Saricicek A, Zorlu N, Yalin N, Hidiroglu C, Cavusoglu B, Ceylan D, et al. Abnormal white matter integrity as a structural endophenotype for bipolar disorder. Psychol Med. 2016;46:1547-58.

98. Mahon K, Burdick KE, Ikuta T, Braga RJ, Gruner P, Malhotra AK, et al. Abnormal temporal lobe white matter as a biomarker for genetic risk of bipolar disorder. Biol Psychiatry. 2013;73:177-82.

99. Lagopoulos J, Hermens DF, Hatton SN, Battisti RA, Tobias-Webb J, White D, et al. Microstructural white matter changes are correlated with the stage of psychiatric illness. Transl Psychiatry. 2013:3:e248.

100. Katz J, d'Albis MA, Boisgontier J, Poupon C, Mangin JF, Guevara P, et al. Similar white matter but opposite grey matter changes in schizophrenia and highfunctioning autism. Acta Psychiatr Scand. 2016;134:31-9.

101. Lenka A, Ingalhalikar M, Shah A, Saini J, Arumugham SS, Hegde S, et al. Abnormalities in the white matter tracts in patients with Parkinson disease and psychosis. Neurology 2020;94:e1876-e84.

102. Lim L, Howells H, Radua J, Rubia K. Aberrant structural connectivity in childhood maltreatment: a meta-analysis. Neurosci Biobehav Rev. 2020;116:406-14.

103. Jenkins LM, Barba $A$, Campbell $M$, Lamar $M$, Shankman $S A$, Leow $A D$, et al. Shared white matter alterations across emotional disorders: a voxel-based metaanalysis of fractional anisotropy. Neuroimage Clin. 2016;12:1022-34.

104. Hiser J, Koenigs M. The multifaceted role of the ventromedial prefrontal cortex in emotion, decision making, social cognition, and psychopathology. Biol Psychiatry. 2018;83:638-47.

105. Dixon ML, Thiruchselvam R, Todd R, Christoff K. Emotion and the prefrontal cortex: an integrative review. Psychol Bull. 2017;143:1033-81.

106. Schmaal L, Hibar DP, Samann PG, Hall GB, Baune BT, Jahanshad N, et al. Cortical abnormalities in adults and adolescents with major depression based on brain scans from 20 cohorts worldwide in the ENIGMA Major Depressive Disorder Working Group. Mol Psychiatry. 2017;22:900-09.

107. Kempton MJ, Salvador Z, Munafo MR, Geddes JR, Simmons A, Frangou S, et al. Structural neuroimaging studies in major depressive disorder. Meta-analysis and comparison with bipolar disorder. Arch Gen Psychiatry. 2011;68:675-90.

108. Koolschijn PC, van Haren NE, Lensvelt-Mulders GJ, Hulshoff Pol HE, Kahn RS. Brain volume abnormalities in major depressive disorder: a meta-analysis of magnetic resonance imaging studies. Hum Brain Mapp. 2009;30:3719-35.

109. Luby JL, Agrawal A, Belden A, Whalen D, Tillman R, Barch DM. Developmental trajectories of the orbitofrontal cortex and anhedonia in middle childhood and risk for substance use in adolescence in a longitudinal sample of depressed and healthy preschoolers. Am J Psychiatry. 2018;175:1010-21.

110. Ward J, Lyall LM, Bethlehem RAI, Ferguson A, Strawbridge RJ, Lyall DM, et al. Novel genome-wide associations for anhedonia, genetic correlation with psychiatric disorders, and polygenic association with brain structure. Transl Psychiatry. 2019;9:327.

111. van der Knaap MS, Vermeulen G, Barkhof F, Hart AA, Loeber JG, Weel JF. Pattern of white matter abnormalities at MR imaging: use of polymerase chain reaction testing of Guthrie cards to link pattern with congenital cytomegalovirus infection. Radiology 2004;230:529-36.

112. van der Voorn JP, Pouwels PJ, Vermeulen RJ, Barkhof F, van der Knaap MS. Quantitative MR imaging and spectroscopy in congenital cytomegalovirus infection and periventricular leukomalacia suggests a comparable neuropathological substrate of the cerebral white matter lesions. Neuropediatrics 2009;40:168-73.

113. de Vries LS. Viral infections and the neonatal brain. Semin Pediatr Neurol. 2019;32:100769.

114. Gottumukkala RV, Romero JM, Riascos RF, Rojas R, Glikstein RS. Imaging of the brain in patients with human immunodeficiency virus infection. Top Magn Reson Imaging. 2014;23:275-91.

115. Holland NR, Power C, Mathews VP, Glass JD, Forman M, McArthur JC. Cytomegalovirus encephalitis in acquired immunodeficiency syndrome (AIDS). Neurology 1994;44:507-14.

116. Nijman J, Gunkel J, de Vries LS, van Kooij BJ, van Haastert IC, Benders MJ, et al. Reduced occipital fractional anisotropy on cerebral diffusion tensor imaging in preterm infants with postnatally acquired cytomegalovirus infection. Neonatology 2013;104:143-50.

117. Benedetti F, Poletti S, Hoogenboezem TA, Mazza E, Ambree O, de Wit $\mathrm{H}$, et al Inflammatory cytokines influence measures of white matter integrity in Bipolar Disorder. J Affect Disord. 2016;202:1-9.

118. Wang Y, Wei Y, Edmiston EK, Womer FY, Zhang X, Duan J, et al. Altered structural connectivity and cytokine levels in Schizophrenia and genetic high-risk individuals: associations with disease states and vulnerability. Schizophr Res. 2020;223:158-65.

119. Swardfager W, Yu D, Ramirez J, Cogo-Moreira H, Szilagyi G, Holmes MF, et al Peripheral inflammatory markers indicate microstructural damage within periventricular white matter hyperintensities in Alzheimer's disease: a preliminary report. Alzheimers Dement. 2017;7:56-60.

120. Rodrigue AL, Knowles EE, Mollon J, Mathias SR, Koenis MM, Peralta JM, et al. Evidence for genetic correlation between human cerebral white matter microstructure and inflammation. Hum Brain Mapp. 2019;40:4180-91.

121. Jiang J, Trollor JN, Brown DA, Crawford JD, Thalamuthu A, Smith E, et al. An inverse relationship between serum macrophage inhibitory cytokine-1 levels and brain white matter integrity in community-dwelling older individuals. Psychoneuroendocrinology 2015;62:80-8.

122. Gianella S, Moser C, Vitomirov A, McKhann A, Layman L, Scott B, et al. Presence of asymptomatic cytomegalovirus and Epstein-Barr virus DNA in blood of persons with HIV starting antiretroviral therapy is associated with non-AIDS clinical events. AIDS 2020;34:849-57.

123. Houenou J, d'Albis MA, Daban C, Hamdani N, Delavest M, Lepine JP, et al Cytomegalovirus seropositivity and serointensity are associated with hippocampal volume and verbal memory in schizophrenia and bipolar disorder. Prog Neuropsychopharmacol Biol Psychiatry. 2014;48:142-8.

124. Ford BN, Yolken RH, Aupperle RL, Teague TK, Irwin MR, Paulus MP, et al. Association of early-life stress with cytomegalovirus infection in adults with major depressive disorder. JAMA Psychiatry. 2019;76:545-7.

125. Dodgeon B, Patalay P, Ploubidis GB, Wiggins RD. Exploring the role of early-life circumstances, abilities and achievements on well-being at age 50 years: evidence from the 1958 British birth cohort study. BMJ Open. 2020;10:e031416.

126. Dufford AJ, Evans GW, Dmitrieva J, Swain JE, Liberzon I, Kim P. Prospective associations, longitudinal patterns of childhood socioeconomic status, and white matter organization in adulthood. Hum Brain Mapp. 2020;41:3580-93.

127. Bowman LJ, Melaragno Jl, Brennan DC. Letermovir for the management of cytomegalovirus infection. Expert Opin Investig Drugs. 2017;26:235-41.

128. Griffiths P, Lumley S. Cytomegalovirus. Curr Opin Infect Dis. 2014;27:554-9. 
129. Kotton CN. CMV: prevention, diagnosis and therapy. Am J Transpl. 2013;13:24-40.

130. Hunt PW, Martin JN, Sinclair E, Epling L, Teague J, Jacobson MA, et al. Valganciclovir reduces $\mathrm{T}$ cell activation in HIV-infected individuals with incomplete $\mathrm{CD} 4+\mathrm{T}$ cell recovery on antiretroviral therapy. J Infect Dis. 2011;203:1474-83.

131. Klenerman $P$, Oxenius A. T cell responses to cytomegalovirus. Nat Rev Immunol. 2016;16:367-77.

132. Patel Y, Shin J, Drakesmith M, Evans J, Pausova Z, Paus T. Virtual histology of multi-modal magnetic resonance imaging of cerebral cortex in young men. Neuroimage 2020;218:116968.

133. Jones DK, Knosche TR, Turner R. White matter integrity, fiber count, and other fallacies: the do's and don'ts of diffusion MRI. Neuroimage 2013;73:239-54. (i) Open Access This article is licensed under a Creative Commons Attribution 4.0 International License, which permits use, sharing, adaptation, distribution and reproduction in any medium or format, as long as you give appropriate credit to the original author(s) and the source, provide a link to the Creative Commons license, and indicate if changes were made. The images or other third party material in this article are included in the article's Creative Commons license, unless indicated otherwise in a credit line to the material. If material is not included in the article's Creative Commons license and your intended use is not permitted by statutory regulation or exceeds the permitted use, you will need to obtain permission directly from the copyright holder. To view a copy of this license, visit http://creativecommons.org/licenses/by/4.0/.

(c) The Author(s) 2021

\section{TULSA 1000 INVESTIGATORS}

Robin Aupperle', Jerzy Bodurka', Justin Feinstein', Sahib S. Khalsa', Rayus Kuplicki', Martin P. Paulus', Jonathan Savitz ${ }^{1}$ and Teresa A. Victor $^{1}$ 